be collected from a member of the wage-earning class. Moreover, it is adequate for the purpose of making district nursing self-supporting, as will be shown hereafter. In the case of a family, 2s. $6 d$. per annum would probably be a sufficient charge, as the mother can, as a rule, do what nursing is required for the children, and only rarely will need more skilled assistance. When feasible, the collection of the annual contributions may be undertaken by the macbinery of the local dispensary or benefit societies, which will, after deducting the cost of collecting, hand over the balance to the District Nursing Association, and in return have their members enrolled on the register of that Association. Another plan would be to inclade the services of the district nurse amongst the benefits a provident dispensary offers to its members, a small capitation charge being levied for the purpose. The total sum contributed towards the expenses of the nursing association per 1000 persons would vary somewhat, according to the relative proportion of unmarried persons and families, and according to the amount charged to each. But, on the basis suggested above, approximarely $£ 25$ per annum would be collected. Thus 4000 members would yield $\$ 100$ towards the expenses of the district nurses, and so on in like ratio. The annual cost of a trained district nurse is roughly estimated ar from $£ 80$ to $£ 100$ a year, so that 4000 members would in the aggregate contribute a sufficient sum for her support. In addition, experience proves that one district nurse is amply sufficient for 4000 persons. Indeed, in many towns with a large artisan population, one nurse suffices for a population of 6000 or 8000 . Hence it follows that upon this provident basis district nursing may readily be made self-supporting. In order to encourage payment in advance of the annual subscription, it would probably be desirable to exact an extra fee of perhaps $5 \mathrm{~s}$. from any person who had neglected to make himself "free of the nurse," and yet desired her services when sickness came.

One objection to this scheme may be raised-viz., that in some homes there is such extreme poverty that even 1s. a year cannot be paid, and yet the visits of the district nurse may be eminently required. This difficulty, which only applies to exceptional cases, may be met, if thought desirable, by adopting such a plan as that in rogue at some provident dispensaries, where subscribers, in return for their contributions, are entitled to free nomination tickets to be reserved for cases of extreme poverty. The recipient of such a ticket would be entitled to the gratuitous services of the nurse. Probably for an annual subscription of $£ 1$ about four such tickets might be given. Where there is actual destitution, the guardians of the poor have coxer, under an order of the Local Government Board dated Jan $27 \mathrm{th}, 1892$, to apply the rates for the purpose of nursing the out.door paupers, as is already done in the case of over 100 unions in various parts of the country. Such a course obviously tends in the long run to keep down the rates by diminishing the number of sick who would be compelled to go to the workhouse infirmary and also by helping to restore to health those who are dependent upon out-door relief. It is probable, therefore, that the guardians of the poor will frequently avail themselves of the occasional services of the district nurse and subscribe to her support.

The question may perhaps be asked, What need is there for the capital fund that is being raised in various localities towards establishing an institute of district nursing, if this can be worked on a provident, self-supporting basis? The reply is that such a fund, although not absolutely necessary, will help to give the movement a good start, by acquiring and furnishing a home for the nurses without deducting anything for the purpose from the contributions of the provident members. Moreover, there are various sick appliances, such as air-cushions, feeders, clinical thermometers, \&c., which should be provided, and which can be lent gratis to provident members when the need arises.

In dealing with rural districts and a scattered population. some modification of the details of this scheme will be required, in adaptation to local circumstances. If on the one hand, the distances to be traversed by the nurse are greater and the number of visits she can pay is consequently reduced, this, on the other hand, will be to some extent compensated for by the more bealthy condition of our rural population, which will less often require her services. But even if the details are altered, it is equally important to maintain a provident basis of work as preferable from its moral and economic aspects to a charitable one. The above remarks have referred especially to localities in which district nursing is being established in commemoration of Her Majesty's sixty years' rejgn. But there can be no great difficulty in introducing this scheme, even where the basis of work has hitherto been a charitable one. The two methods may for a time be worked side by side until the provident system is gradually substituted for the less desirable one.

In conclusion, this method of organisation presents several distinct advantages. First, the institute of district nursing. when once started, will be independent of charity, and can be maintained on a self-supporting, and therefore healthy, basis. Secondly, the working classes, instead of being encouraged to depend on the gratuitous help of others, are encouraged to make provision against the day of sickness, and a habit of thrift is promoted. Thirdly, the services of the district nurses will be more appreciated than if renderect gratuitously. Experience teaches that people value most what they pay for, and assuredly this applies to the question under discussion. The cumulative weight of these arguments must be readily apparent. No laments will be heard that the funds are insufficient for the work, and that an inadequate staff of nurses vainly endeavours to cope with an overwhelming amount of sickness. The institution becomes a help-myself nursing organisation, and enables the poor, by voluntary combination and at a trifing cost, to provide for skilled nursing, just as, by means of a provident dispensary, they now provide for medical aid and medicine. Such an institution, established on a provident, self-supporting basis, will be a power for good in a district, and will minister to the social welfare of the working classes. Reading.

\section{ANOTHER METHOD OF AMELIORATING BY OPERATION OTHERWISE IN- CURABLE INCONTINENCE OF URINE.}

BY WM. ALEXANDER, M.D.R.U.T., F.R.C.S. ENG., SURGEON TO THE ROYAL SOUTHERN AND WORKHOUSE HOSPITALS, LIVERPOOL.

IN the fourth volume of the British Gynecological Journal, p. $2 \mathrm{~L} 5$, an uncorrected paper of mine appears, entitled "A Method of Treating Incontinence of Urine in the Female in Cases hitherto considered to be Beyond the Resources of Surgery." In that paper a fair amount of success was obtained by turning a paralysed urethra in to the rectum, the latter viscus being able to retain the urine so long: as to make the patient comfortable. This patient died about twelve months after operation, but not before she had put beyond doubt the practical use of this method of relief. Her condition was much inferior to that of nature, as she was practically in a condition resembling diarrhœa, having from six to eight evacuations daily, but at the same time the condition was a great improvement on her previous state, where she was continually wet and "reeking" with a urinous odour. In the same paper another case is described where an attempt was made to relieve a patient whose urethra had sloughed away. The same principle was adopted of depending on the rectal sphincter, but although we were on the verge of success the patient left the hospital before the arethral opening was closed.

Two years ago, on April 30th, 1895, a woman, aged thirtyo four years, came into the Royal Southern Hospital suffering from incontinence of urine that had existed for the past fourteen years. She had always been delicate (tuberculous), and fourteen years ago she had diseased bone removed from the sacrum. It was after this operation that her urinary troubles began. At first she could not pass urine, then it began to dribble away, and she could not retain it for any length of time, and soon it flowed away constantly except when she was asleep, and then she would keep fairly dry for short periods. Examination on admission showed that she had no control over the rectum or urethra, the sphincters were quite flaccid, and the mucous membrane everted and congested. The uterus dropped down, and the lower part of the vaginal walls was everted. The whole vulva and perineum were congested, excoriated, and covered with salts and mucus that adhered to the hairs and skin, and the whole region looked, smelt, and felt very unpleasant. The idea of 
diverting the urine from the imperfect vesical reservoir into a rectal one, as had been done in the previous cases, was not applicable here, as the rectal sphincter was, in this case, paralysed, and would not hold water. I could find no reference to such a case in the manuals of surgery or in monographs on urinary diseases, and it was only after much thought that I determined to close the urethral opening, and make a permanent suprapubic opening as high as possible and to which an appliance could be fired that would carry off the urine. How this idea was successfully carried out I will now proceed to show. The formation of a suprapubic opening did not present any difficulties, as the bladder could be pushed up into the wound by the aid of a catheter. The bladder wall was stitched to the wound in the skin, and the wound allowed to heal before the urethra was closed. The closure of the urethra is apparently a simple operation, but in practice I found it very difficult. Saprapubic drainage is very imperfect. The tube in the bladder becomes surrounded by mucous membrane and is practically closed, whilst the urine issues by the side of the tube, and, worst of all, the forces of nature tend to send the stream by the old channel, the urethra. Hence union of the plastic wound to close the urethra is not always or of ten sound along the whole line of suture the first time, and several operations were required in this case before closure was complete Experience suggests the following directions to the operator who wishes to close the wrethra: First, insert a thin elastic ring pessary in to the bladder through the suprapubic opening, which, when it expands, is to Tie in the fundus vesicæ, with part of its circumference over the inner orifice of the urethra. This ring keeps the bladder from contracting, converts it into a pool that can be drained by a syphon, stops the natural tendency that exists to force the urine into the urethra, and blocks that opening. This extraordinary procedure was of great value, and I would certainly adopt it again. Its insertion, retention, and removal did not present any difficulties or inconveniences, although, theoretically, it should have produced both. The arethra is best closed by splitting the mucous and muscular coats, turning the former in towards the bladder, and stitching together its raw and now external surfaces with mumerous fine catgut sutures. The raw surfaces of the muscular coat are simply brought together by fine silkworm gut sutures. The method of drainage is simplicity itself. It consists in the ivory nozzle of a Higginson's syringe with the curves of the neck and

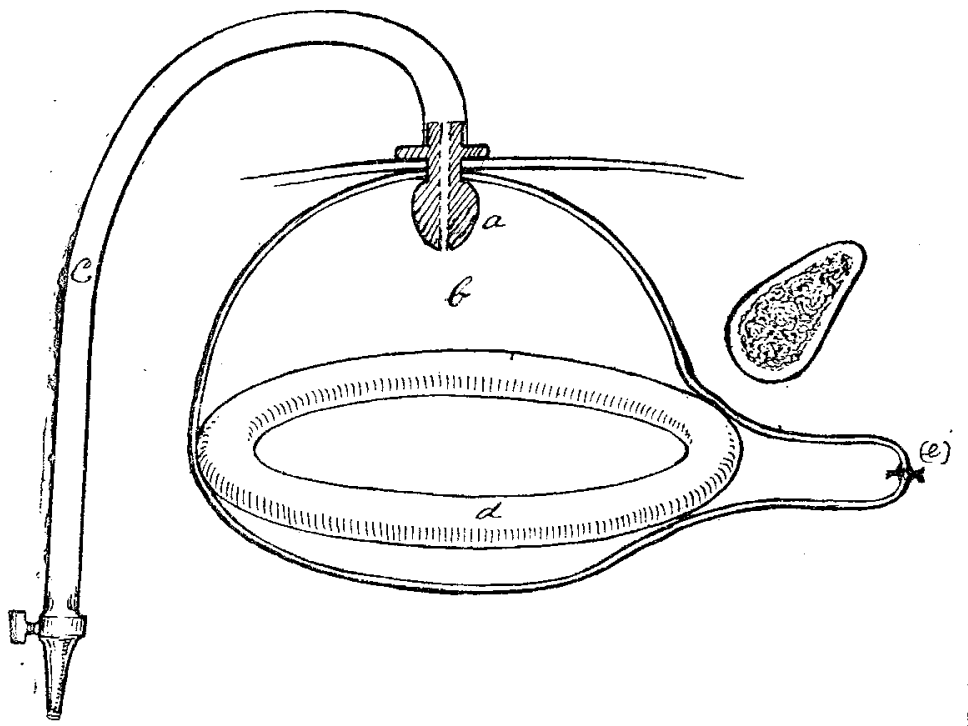

The diagram represents the ivory nozzle $(a)$ in the bladder $(b)$, with its tube and stopcosk $(c)$, the pessary $(d)$ lying in position in the bladder during the closure of the urethra, and the method of closure of the urethra $(e)$.

body of the nozzle exaggerated so as to have the shoulder below the neck more pronounced. A rubber tube with a tap at the end that can be brought through the dress and so allow the bladder to be empted with more than usual facility completes the apparatus. It is really self retaining, but a bandage round the body prevents the ejection of the tube under any great strain or awkward twist of the body. When the tap is closed the urine collecting distends the bladder and the tabe, and as these become distended the internal hydraulic pressure keeps the shoulder of the nozzle applied to the inner margin of the opening until the patient feels the distension and lets the water flow away. Dr. J. A. Craig and I were planning all sorts of apparatus to fit the aperture and keep the patient dry, but we found that the Higginson's nozzle was more effectnal than all our perfect theoretical notions, and it took us some time to realise theoretically how such a simple contrivance was effectual. The patient left the hospital on Aug. 8th, 1896. She came to show herself on March 17th, 1897, with the apparatus in good working order, her skin quite dry, and healthy, no urinary odour about her, and her linen clean and unstained. She can manage quite well, no urine escaping except a little sometimes at night when she is asleep. Her uterus is protruding, and we have recommended an advancement of the perineum to support it, but as far as the incontinence is concerned the results have exceeded all our expectations. It supersedes completely the rectal reservoir idea, and does not come far short of affording all the advantages of the natural condition.

Liverpool.

\section{Clinital atotes:}

\section{MEDICAL, SURGICAL, OBSTETRICAL, AND THERAPEUTICAL.}

\section{NOTES ON THE INJURIES IN THREE CASES OF PERSONS STRUCK BY LIGHTNING.}

By E. Pocklingtoy, M.R.C.S. Eng., L.S.A.,

AND

R. T. Poole Colmyns, M.R C.S. ENG.

As cases of injury from lightning are comparatively rare in this country the following may be of interest, having recently occurred in our practice.

On June 24th, at about 6 P.M. we were informed that one man and two boys had been injured on Wimbledon Common. The boys were aged respectively nine and eleven years, and had taken refuge from the storm in a temporary wooden structure without a roof, but they had apparently taken a sheet of galvanised iron, and propped it up on the wood as a shelter. When seen they were cold and collapsed, with a slow pulse, and seemed dazed; hearing was much impaired, but the eyesight was not affected; the elder one had a patch of hair, 1 in. by 3 in, over the left parietal bone singed and a red bruise on the left forearm; he complained of shooting pains in both wrists, the right being the worse. During the night both of the patients were violently sick, but in the morning they seemed but little the worse for the accident, except that they were slightly deaf. On examining the clothes after they were dry a dark round patch, the size of a shilling, was seen on the cap of the elder one, and two singed lines on the inner side of the left shirt sleeve.

The man was aged nineteen years, and was quite dead when found. A necropsy was made twenty-one hours after death. The body was well nourished. Rigor mortis was just commencing. The hair over the left parietal bone and on the left half of the body and the left leg was singed; there was a burn over the left clavisle where the brace buckle had rested, and there were also small round burns corresponding to the eyelet holes of the boot on the dorsum of the left foot. Arborescent lines were present over the whole of the body, being most marked on the left side of the chest and on the left thigh. On removing the skull cap a minute fissure which corresponded with the singed patch of hair was found; the vessels of the dura mater were gorged and the left ventricle of the brain contained much fluid while the right contained only a normal quantity; the blood throughout the body was fluid and there was only one small clot on the left side of the heart; all the organs were much congested. Oo examining the clothes a small hole was found in the cap and the inside lining was much torn. The left sock was in rags and the left boot was burst open along the outer side. The sole was intact; the nails round the sole were brass, but there had evidently been three large steel nails as in the usual place for these there were holes with charred edges.

Wimbledon. 